\title{
HOW MANAGEMENT EFFORTS OF A LARGE HYDROPOWER FIRM IMPACT SUSTAINABILITY IN THE COLOMBIAN ANDES: A MULTIVARIATE ANALYSIS OF SOCIETY'S PERCEPTIONS
}

\author{
DANIEL CORTÉS-BORDA, JORGE-ANDRÉS POLANCO \& MANUELA ESCOBAR-SIERRA \\ Faculty of Economic and Administrative Sciences, University of Medellin, Colombia
}

\begin{abstract}
When it comes to sustainability, watersheds and hydropower firms must be conceived as a whole. Namely, hydropower dams impact the three dimensions of sustainability of watersheds, while dams' lifetime is lowered by unsustainable practices taking place in the watersheds. Management of hydropower firms aiming at sustainability might ensure the long-term use of dams without compromising ecosystems and society's welfare. We aim to assess the impact of management efforts of a large hydropower firm on the sustainability of the influenced watersheds from the perceptions of society. We build on survey data assessing the social perception of the impacts caused by a large hydropower plants operation; and the firm's management efforts aiming at sustainability. To this end, we perform a stepwise multilinear regression of ad-hoc impact management indices (independent variables) and impact indices (dependent variables). Data comprises more than 600 surveys from community, policymakers and industry, from two watersheds in Colombian Andes. Results revealed a positive correlation between all the impact indices and the management indices concerning environment and economy-society. The remaining management indices showed no (or low) correlation with impacts. Findings suggest that, despite firm's sustainability awareness, society perceives low positive impact in due to (what they consider) firm's few impact management efforts in environmental indices (i.e., erosion and deforestation) and socio-economic indices (i.e., income alternatives in agriculture, fisheries and tourism activities). Other efforts are not perceived as (positive or negative) consequences of the impact. Correlation results provided valuable information, for scholars and practitioners, on the interaction of dams and watersheds. On one hand, the theoretical implications showed how a holistic approach of sustainability is needed to better understand the complexity of this relationship. On the other, the management implications gave insights on how a large hydropower plant can operate in the long term while causing a positive impact on ecosystems and the local society.
\end{abstract}

Keywords: sustainability, hydropower, stepwise regression, social perception, watershed, social impact, environmental impact.

\section{INTRODUCTION}

The United Nations Sustainable Development Goals (SDGs) concerning energy aim to achieve global access to energy, reduce the severe health impacts of air pollution, and tackle climate change, which altogether might be achieved by substantially increasing the share of renewable energies. Hydropower, today's primary renewable energy source, plays a crucial role in meeting the SDGs [1] since it helps to mitigate greenhouse gas emissions while reducing reliance on imported fuels, and it is an inexpensive power source that adapts to the different needs and possibilities of the emerging and developed economies [2]. Moreover, storing water in hydroelectric dams provides grid stability [3] and offers other advantages [4]-[7] that are particularly interesting for emerging economies (e.g., drought management, irrigation, water supply, flood control, aquaculture, tourism and other job opportunities). 
Although hydropower has numerous benefits, it has been intensely criticized [8]-[10] due to its social and environmental adverse effects [11]-[14] related to its extractive nature [15]. That is, the construction and operation of dams lead to population relocation, social conflicts, landslides, habitat changes, among other relevant issues that threaten social and biodiversity welfare [15], [16]. It is well known that the social impact of large hydroelectric dams leads to social transformations [17] derived from the inequitable distribution of positive and negative impacts among the stakeholders [18]. Conflicts between hydropower firms and society have raised questions related to the sustainability of dams and the rights of the watershed's inhabitants [19]-[21]. Moreover, emerging economies are particularly vulnerable to climate induced hydrological [22], [23] changes that threaten hydropower projects (i.e., erosion and sedimentation that shorten their lifetime and their production capacity [24]).

Lessons learned from the past have taught that social and environmental issues have restricted the hydropower expansion projects of two of the world's leading hydropower producers, China and Brazil [1]. Hence, the management of hydropower projects require guidance in environmental, social, financial, and technical sustainability criteria, from the joint perspective of industry, civil society, policy makers, and financiers [25]-[27]. Practical solutions to overcome hydropower drawbacks include developing of protective measures [26]; performing comprehensive impact assessments [7], risk evaluations and management plans involving the stakeholders [29], [30]; engaging stakeholders in the decisions related to the watershed [31]-[33]; and a benefit sharing scheme [34], [35]. However, adopting a holistic sustainability approach in the management of large hydroelectric firms [11] (e.g., corporate sustainability [36]) could be a solution to create value while strengthening the social and environmental development of watersheds.

Colombia is an emerging economy with a large hydropower potential. The growing energy demand along with the national government priorities [16] placed Colombia among the top hydropower producers in the world [37], and it is expected to continue expanding [38]. Unfortunately, the intensive deployment of hydropower in Colombia has led to severe accidents [39] and environmental, social, and armed conflicts [15], [16], [18], [40], [41] often derived from deep inequalities [42], the lack of trust of the stakeholders and the weak interventions of the state [43].

The sustainability of the hydropower sector in Colombia has gained increasing awareness and financial support [44]. In recent years, sustainability issues related to hydropower in Colombia has been assessed, i.e., the management of sediments [45], [46], the sediments generation according to the land use [47], the payment for ecosystem services [48], the benefit sharing scheme [35], the governance for sustainability in a context of violence [20], the equity and sustainability of water allocation [49] and the political events that have led to social conflicts related to hydropower [16]. Other authors have modelled different scenarios and proposed policies to aid in the decision-making process [50]. In terms of corporate sustainability, Polanco [43] identified the relationship between the strategy and the political stance of the hydropower companies. Despite the numerous studies related to the sustainability of hydropower in Colombia, it is still necessary to establish a quantitative cause-effect relationship between sustainability and the management actions taken in hydropower firms.

In a recent project intitled "A new measurement system design for monitoring sustainability performance of hydropower" our research team surveyed more than 600 society members (including community, policymakers and industry) from two different watersheds in Colombian Andes to assess the social perception of the impacts caused by the operation of two large hydropower plants and the firm's management actions to tackle such 
impacts. Going beyond the surveys, we aim to assess the impact of management efforts of a large hydropower firm on the sustainability of the influenced watersheds from the perceptions of society. To this end, we performed a stepwise multilinear correlation of adhoc sustainability management indices (independent variables) and impact indices (dependent variables) to establish a correlation that reveals valuable information (for scholars and practitioners) on the effectiveness of the firm's actions. To the best of our knowledge, this is the first study (in the Colombian Andes) establishing a cause-effect quantitative relationship between the impact of hydroelectric dams and the management efforts aiming at sustainability.

The remainder of this document is organized as follows. Section 2 establishes the hypothesis of our research, followed by a detailed description of the nature of data and the description of the statistical methods here used. Section 3 presents the main findings of the stepwise correlations and its implications, while conclusions that might be profitable for scholars and practitioners are drawn in Section 4.

\section{METHODS}

In this work we aim to establish cause-effect relationships between impact management efforts and sustainability. To do so, here we formally state the hypothesis to be tested through a stepwise regression of ad-hoc sustainability indices. Then, we provide details on the survey data and the construction of impact indices (assessing the social perception of the impacts caused by two large hydropower plants), and the impact management indices (assessing the social perception of the firm's management efforts to tackle such impacts). We examine cause-effect relationships by performing stepwise correlations of the impact and impact management indices (according to their location and social segment).

\subsection{Hypothesis}

The hypothesis that we aim to probe is as follows:

H1: Colombian Andes society perceives the impact of management efforts to improve the sustainability of the watersheds of a large hydropower firm on the three dimensions of sustainability, and its interactions.

\subsection{Data}

The data set consists of 694 social perception surveys made in 2018. Data belongs to two different watersheds of the Colombian Andes (R1 and R2, with 377 and 317 surveys, respectively), and three different social segments: Community (Com), Policymakers (Pol), and Industry (Ind) (with 605, 68 and 21 surveys, respectively). The measuring instrument comprises 25 questions measuring the perception in 1-5 Likert scale, where 5 is the most positive perception. A translated to English version of the 25-question survey used as measuring instrument is provided in the Appendix. The 25 questions are divided as follows: questions Q1-Q10 assess the social perception of impact, questions Q11-Q25 assess the social perception of impact management. The resulting 25 questions concerning evaluate two of the three dimensions of sustainability, and the interactions of the three dimensions of sustainability. For the sake of simplicity, we refer to the ensemble of the (aforementioned) two dimensions of sustainability and the three interactions as "categories."

We rely on the categories previously defined by Polanco [20], which are as follows: the environmental category (Env) concerns climate change, biodiversity, and the condition of natural resources, water, and soil; the social category (Soc) refers to building social capital, 
trust, relationships, and organizational networks; the environment-economy category (EnvEco) is related to the economy of natural resources (supply and demand), pollution of the environment, and basic sanitation; the economy-society category (Eco-Soc) is associated to activities for subsistence, food security, production organization, and commercialization of farm products; and the environment-society category (Env-Soc) entails training, consciousness, and environmental culture in the territory. Noteworthy, the economic dimension of sustainability was not addressed here since it was studied in deep by Polanco et al. [51].

\subsection{Indices construction and preliminary analysis}

We start by treating the results of the 25 questions as variables. We validated an eventual stepwise correlation by proving their linear independence via the rank of the matrix of variables (25 questions and 694 observations). Since, linear regressions with a large set of variables may lead to poor model predictions, we attempted to reduce the dimension of the problem without a significant loss of information by grouping variables through a principal component analysis (PCA). The PCA did not lead to linear combinations of variables leading to a reduced model (which fits the results of the linear independence test).

Since variables were not significantly correlated, we grouped variables according to their categories, leading to five impact indices (I1-I5) and five impact management indices (I6-I10), i.e., one impact index and one impact management index per category. Fig. 1 depicts the data structure and how questions are grouped (according to their category) to create impact indices and impact management indices.

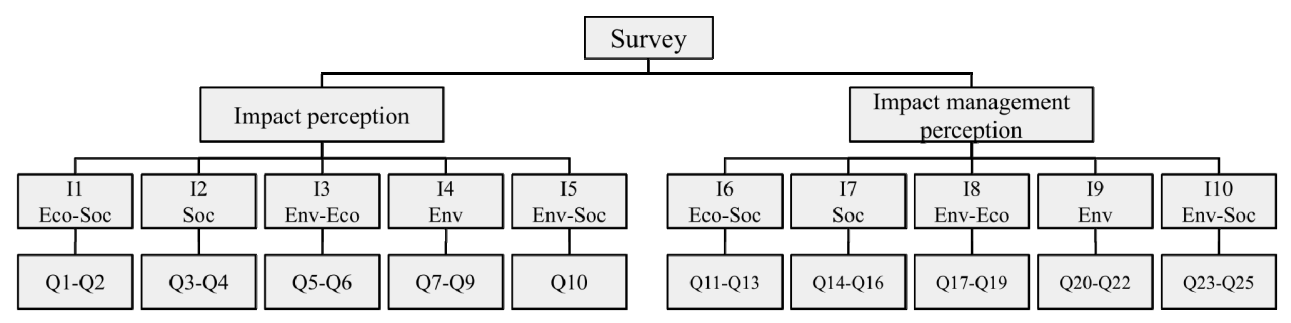

Figure 1: Data structure and indices construction.

Indices are calculated as the arithmetic mean of all the variables belonging to the same category (see Fig. 1). As an example, let us consider index I1 (perception of impact in the socioeconomic category). The index I1 is a 694-element column vector calculated as the average of columns corresponding to questions Q1 and Q2, where questions Q1 and Q2 represent the impact perception of the 694 surveyed individuals, in the Eco-Soc category. We verified that there is no multicollinearity in the new matrix of indices (10 indices and 694 observations) by calculating the rank the matrix.

As a complementary analysis of the stepwise regression, we compared the average level of perception in each index and explored if there are significant differences in the perception level of impact and impact management according to the geographical locations and the social segments via two-way ANOVA. 


\subsection{Stepwise regression}

Stepwise regression is a well-known method that contrasts numerous multivariate linear regression models and selects the one with the best-fit of data [52]. The algorithm starts with an initial model and makes successive steps to improve it by adding and removing terms according to the significance of the independent variables (which is determined by an F-test hypothesis in each linear regression). In each step, the stepwise regression method uses the least squares method to estimate the model coefficients. The stepwise regression is an iterative process that terminates when the model does not improve with further steps.

We used the MATLAB built-in stepwise regression algorithm to validate our hypothesis. In this correlation, the impact perception indices (I1-I5) represent the dependent variables and the impact management perception indices (I6-I10) represent the independent variables.

Thereby, per each impact perception index, the stepwise regression method selects which of the five independent variables make significant contributions to the multilinear model. Since the perception of impacts and impact management might be significantly different according to the geographical location and social segment, we examined one stepwise regression for each impact index, for each region, and for each social segment (including the global set of data, denoted as 'All'). This approach leads to 30 stepwise multilinear models shedding light on the cause-effect relationship between the impact management and the sustainability impacts derived from the intervention of hydropower in the Colombian Andes.

\section{RESULTS AND DISCUSSION}

In a preliminary analysis we compared the average perception values in the studied groups, which revealed that, as a general trend, the industry has the most favorable perception of impact and impact management, while the community is the most pessimistic social segment. Regarding the geographical location, in most of the impact and impact management indices, Z1 exhibited a better perception than Z2. At first glance, we observed differences in the perception level among groups, however the two-way ANOVA assessment discloses which of the differences are statistically significant.

Results from the two-way ANOVA showed that the perception of Z2-Com, the most pessimistic group, is significantly different from the other groups in all the indices, except for I10 (impact management index related to training, consciousness, and environmental culture in the territory). The ANOVA results also showed that, excluding Z2-com, all the significant differences in perception are related to impact management indices, and not in impact indices. That is, the group Z1-com presents significant differences in indices I6, I7, I8, I9; the group Z1-Pol is significantly different in index I8; and the groups Z1-Pol and Z2Pol presents differences in I6. Later in this section, we will develop joint analysis of the results of the two-way ANOVA and the stepwise regressions.

Once we validated that there is no multicollinearity in the matrix of indices (10 indices and 694 observations) by calculating the rank of the full data matrix, we performed 30 multilinear stepwise regression models considering different geographical locations and social segments. The alpha value used to contrast the hypothesis was $1 \%$ (e.g., variables considered in each regression model have a significance level of, at least, 99\%).

The results of the coefficient of determination $\left(\mathrm{R}^{2}\right)$ of each stepwise correlation model (following a color scale) are given in Table 1. It is worth mentioning that we aim to identify cause-effect relationships between the impact management indices and the impact indices, and do not aim to predict a precise value of the impact as a function of the impact 
management. Hence, the relatively low values of the $\mathrm{R}^{2}$ are not a major concern for the scope of this study.

Table 1: Coefficient of determination $\left(\mathrm{R}^{2}\right)$ of each stepwise model.

\begin{tabular}{|c|c|c|c|c|c|c|}
\hline \multirow{2}{*}{ Social segment } & \multicolumn{7}{|c|}{ Coefficient of determination $\left(\mathrm{R}^{2}\right)$} \\
\cline { 2 - 7 } & I1 Eco-Soc & I2 Soc & I3 Env-Eco & I4 Env & I5 Env-Soc & Average \\
\hline Ind & & 0.39 & 0.20 & & 0.47 & 0.35 \\
\hline Pol & & 0.09 & 0.19 & 0.14 & 0.12 & 0.13 \\
\hline Com & 0.38 & 0.38 & 0.36 & 0.37 & 0.28 & 0.35 \\
\hline Z1 & 0.27 & 0.27 & 0.35 & 0.26 & 0.19 & 0.27 \\
\hline Z2 & 0.30 & 0.30 & 0.26 & 0.38 & 0.25 & 0.30 \\
\hline All & 0.37 & 0.38 & 0.37 & 0.38 & 0.29 & 0.36 \\
\hline Average & 0.33 & 0.30 & 0.29 & 0.31 & 0.27 & \\
\hline
\end{tabular}

Remarkably, three out of the 30 models are absent. No (or low) correlations entail that the studied social segment does not perceive any (positive or negative) effect of the management efforts to improve sustainability in the sustainability performance of the watershed. Industry and policymakers do not perceive a direct relationship between the Eco-Soc impact and any of the impact management indices. Similarly, the industry does not perceive correlations between the environmental impact and any impact management index. In addition, by comparing the $\mathrm{R}^{2}$ average values, we observe that the policymakers' segment presents the weakest cause-effect correlations. The fact that industry and policymakers exhibit low and absent correlations could be explained due to the local economic activities are not directly impacted by the operation of the hydroelectric dams.

We present in Table 2 the stepwise regression models (i.e., variable coefficients and intercept). By assessing the frequency of the impact management indices that appeared in correlations, we observed that I6 (Eco-Soc) and I9 (Env) appeared in $60 \%$ of the correlation models, followed by I10 (Env-Soc) which is present in $23.3 \%$ of the models, and I7 (Soc), and I8 (Env-Eco) which appeared in $20 \%$ of the models.

The frequent appearance of indices I6 and I9 (firm's efforts to improve economic activities of local inhabitants, and firm's efforts in environmental protection and conservation, respectively) in the correlation models could be due to such indices are strongly associated to primary sector economic activities (the main economic activities in $\mathrm{Z1}$ and Z2). Therefore, the firm's actions promoting income alternatives in agriculture, fisheries and tourism activities; as well as the actions to prevent soil erosion and deforestation (which directly affects the availability of primary sector raw materials and products) are perceived by the society as a direct cause of sustainability improvement. By examining correlations of the remaining impact management indices, we observe that, in most of the social segments, the firm's actions building social capital (I7) is perceived by the society as a direct cause of trust and organizational networks improvement (I2), and the promotion of environmental culture (I5) (only in the group All). While the efforts made on the economy of natural resources (supply and demand), pollution of the environment, and basic sanitation (I8) are perceived (mainly by Z1) as a cause of improvement in social (I2), environmental-economic (I3), environmental (I4) categories. The effect of training, consciousness, and environmental culture in the territory (I10) over indices I1, I3, I4 and I5 appears to be conflicting since there are positive and negative correlations with the impact indicators. 
Table 2: Stepwise regression models results.

\begin{tabular}{|c|c|c|c|c|c|c|c|}
\hline \multirow{2}{*}{$\begin{array}{l}\text { Impact } \\
\text { indicator }\end{array}$} & \multirow{2}{*}{$\begin{array}{c}\text { Social } \\
\text { segment }\end{array}$} & \multicolumn{6}{|c|}{ Coefficient values } \\
\hline & & I6 Eco-Soc & I7 Soc & I8 Env-Eco & I9 Env & I10 Env-Soc & Intercept \\
\hline \multirow{6}{*}{ I1 Eco-Soc } & Ind & & & & & & \\
\hline & Pol & & & & & & \\
\hline & Com & 0.77 & & & 0.23 & & -0.04 \\
\hline & $\mathrm{Z1}$ & 0.61 & & & 0.33 & & 0.15 \\
\hline & $\mathrm{Z} 2$ & 0.76 & & & & 0.25 & -0.26 \\
\hline & All & 0.74 & & & 0.21 & & 0.11 \\
\hline \multirow{6}{*}{ I2 Soc } & Ind & & 0.60 & & & & 1.62 \\
\hline & Pol & & 0.43 & & & & 2.12 \\
\hline & Com & 0.50 & 0.30 & 0.20 & & & 0.60 \\
\hline & $\mathrm{Z1}$ & 0.43 & & 0.33 & & & 1.35 \\
\hline & $\mathrm{Z} 2$ & 0.40 & 0.36 & & & & 1.12 \\
\hline & All & 0.46 & 0.34 & & & & 1.16 \\
\hline \multirow{6}{*}{ I3 Env-Eco } & Ind & & & & 0.74 & & 1.26 \\
\hline & Pol & & & & & 0.53 & 1.81 \\
\hline & Com & 0.52 & & & 0.40 & & 0.78 \\
\hline & $\mathrm{Z1}$ & 0.24 & & 0.28 & 0.42 & & 0.75 \\
\hline & $\mathrm{Z} 2$ & 0.42 & & & 0.43 & -0.21 & 1.52 \\
\hline & All & 0.50 & & & 0.39 & & 0.86 \\
\hline \multirow{6}{*}{ I4 Env } & Ind & & & & & & \\
\hline & Pol & & & & 0.52 & & 1.60 \\
\hline & Com & 0.38 & & 0.24 & 0.40 & -0.24 & 0.67 \\
\hline & $\mathrm{Z1}$ & 0.33 & & 0.30 & & 0.23 & 0.33 \\
\hline & $\mathrm{Z2}$ & 0.40 & & & 0.49 & -0.21 & 0.97 \\
\hline & All & 0.38 & & 0.18 & 0.40 & -0.19 & 0.68 \\
\hline \multirow{6}{*}{ I5 Env-Soc } & Ind & 0.93 & & & & & 0.45 \\
\hline & Pol & & & & 0.31 & & 3.01 \\
\hline & Com & 0.14 & & & 0.66 & & 1.27 \\
\hline & $\mathrm{Z1}$ & & & & 0.39 & 0.35 & 1.35 \\
\hline & $\mathrm{Z} 2$ & & & & 0.69 & & 1.40 \\
\hline & All & & 0.13 & & 0.62 & & 1.38 \\
\hline \multicolumn{2}{|c|}{ Average } & 0.49 & 0.36 & 0.25 & 0.45 & 0.06 & \\
\hline
\end{tabular}

Next, we examined the magnitude and sign of the variable coefficient values. A fasttrack approach to compare the contribution of variables to the models consists of comparing the average of the variable coefficients (excluding zeroes). From this comparison we observed that, I6 and I9 are not only appearing frequently but also their contribution is higher than other variables. Noteworthy, most of the variable coefficients shown in Table 2 are positive, except some of the variable I10 (Env-Soc) (in I3 Z2 and I4 Com, Z2 and All). The positive correlations among cause-effect variables were expected since impact management efforts are intended to improve sustainability. The few negative correlations 
require more studies to disclose whether an eventual reverse effect of the management actions aiming at sustainability. However, since the magnitude of the negative variable coefficients is low (the average variable of the I10 variable coefficient is close to zero), the negative values could be due to noise, which would imply no correlation of I10 with I1-I5 instead of a reverse effect between actions and sustainability.

Finally, we performed a joint analysis of the ANOVA and stepwise regression results to link the correlation level with the level of positive perception. Noteworthy, social groups with highly positive perception (i.e., policymakers and industry) present (in general) weak correlations between impact and impact management. The fact that strong cause-effect correlations do not appear in groups with a better perception entails that their positive perception cannot be ascribed to the effectiveness of the firm's management efforts. Moreover, the absent correlations in such groups may suggest that the impact management efforts done in the indicators that are not correlated are not even perceived by these social groups. The joint analysis also revealed that the most pessimistic groups (e.g., group Z2Com) perceives an evident cause-effect relationship between sustainability and impact management (i.e., present high correlation values between impact and impact management). This may suggest that, despite the firm's sustainability awareness and the significant efforts made to improve the sustainable development in the watershed, these groups perceive that the impact management efforts in are low.

\section{CONCLUSIONS}

After performing a stepwise regression model, we can confirm our hypothesis. In fact, Colombian Andes society perceives the impact of management efforts to improve the sustainability of the watersheds of a large hydropower firm on the three dimensions of sustainability, and its interactions.

Information retrieved from this study could shed light on where to concentrate more impact management efforts, and which efforts might be evaluated (since they are not being perceived). Particularly, impact management efforts perceived as direct cause of improvement of the local sustainability are those made in improving the economy of natural resources, reducing environmental pollution; making basic sanitation; preventing climate change; and protecting biodiversity, natural resources, water, and soil. Whereas management efforts that are less evidently perceived as a cause of sustainability improvement are those made on strengthening social capital, trust, relationships, organizational networks; improving activities for subsistence, food security, production organization, commercialization of farm products; and training, creating consciousness, and environmental culture in the territory.

Despite the hydropower firm's increasing awareness on sustainability, local inhabitants still do not perceive the firm's impact management actions as an attempt to improve the sustainability of the region. Making progress in sustainability would require a shared awareness of sustainability among all the stakeholders.

Correlation results provided valuable information, for scholars and practitioners, on the interaction of dams and watersheds. On one hand, the theoretical implications showed how a holistic approach of sustainability is needed to better understand the complexity of this relationship. On the other, the management implications gave insights on how a large hydropower plant can operate in the long term while causing a positive impact on ecosystems and the local society. 


\section{ACKNOWLEDGEMENTS}

The authors would like to acknowledge Josep-Maria Mateo Sanz, from the Rovira i Virgili University, Tarragona, Spain, who provided support in the preliminary statistical analysis. The authors would like to thank to the Colombian Ministry of Science, Technology and Innovation (Minciencias) for the funding 80740-663-2020.

\section{APPENDIX}

Table A1: Description of question subjects and indices. (Note: textual questions are not provided in Table A1 since the same subjects were differently written according to the social group).

\begin{tabular}{|c|c|c|}
\hline Type of indices & Indices & Question subject \\
\hline \multirow{10}{*}{$\begin{array}{l}\text { Impact perception } \\
\text { indices }\end{array}$} & \multirow{2}{*}{$\begin{array}{l}\text { I1: Eco-Soc } \\
\text { Activities for subsistence, food security, } \\
\text { production organization, and } \\
\text { commercialization of farm products }\end{array}$} & Q1: Income increase \\
\hline & & Q2: New income sources \\
\hline & \multirow{2}{*}{$\begin{array}{l}\text { I2: Soc } \\
\text { Building social capital, trust, relationships, and } \\
\text { organizational networks }\end{array}$} & Q3: Participation in decisions \\
\hline & & Q4: Trust in neighbours \\
\hline & \multirow{2}{*}{$\begin{array}{l}\text { I3: Env-Eco } \\
\text { The economy of natural resources (supply and } \\
\text { demand), pollution of the environment, and } \\
\text { basic sanitation }\end{array}$} & Q5: Forest and soil protection \\
\hline & & $\begin{array}{l}\text { Q6: Water quality and biodiversity } \\
\text { availability }\end{array}$ \\
\hline & \multirow{3}{*}{$\begin{array}{l}\text { I4: Env } \\
\text { Climate change, biodiversity, and the condition } \\
\text { of natural resources, water, and soil }\end{array}$} & Q7: Amount of fish in water bodies \\
\hline & & Q8: Landslidings reduction \\
\hline & & Q9: Overflows reductions \\
\hline & $\begin{array}{l}\text { I5: Env-Soc } \\
\text { Training, consciousness, and environmental } \\
\text { culture in the territory }\end{array}$ & Q10: Nature caring awareness \\
\hline \multirow{15}{*}{$\begin{array}{l}\text { Impact } \\
\text { management } \\
\text { perception indices }\end{array}$} & \multirow{3}{*}{$\begin{array}{l}\text { I6: Eco-Soc } \\
\text { Activities for subsistence, food security, } \\
\text { production organization, and } \\
\text { commercialization of farm products }\end{array}$} & $\begin{array}{l}\text { Q11: Improvement of economic } \\
\text { activities }\end{array}$ \\
\hline & & $\begin{array}{l}\text { Q12: Tool promoting economic } \\
\text { activities }\end{array}$ \\
\hline & & $\begin{array}{l}\text { Q13: Players promoting economic } \\
\text { activities }\end{array}$ \\
\hline & \multirow{3}{*}{$\begin{array}{l}\text { I7: Soc } \\
\text { Building social capital, trust, relationships, and } \\
\text { organizational networks }\end{array}$} & Q14: Participation in local decisions \\
\hline & & Q15: Trust in players \\
\hline & & Q16: Tools motivating trust in actors \\
\hline & \multirow{3}{*}{$\begin{array}{l}\text { I8: Env-Eco } \\
\text { The economy of natural resources (supply and } \\
\text { demand), pollution of the environment, and } \\
\text { basic sanitation }\end{array}$} & Q17: Nature use \\
\hline & & $\begin{array}{l}\text { Q18: Tools leading to good practices } \\
\text { in nature use }\end{array}$ \\
\hline & & $\begin{array}{l}\text { Q19: Players involved in the good use } \\
\text { of nature }\end{array}$ \\
\hline & \multirow{3}{*}{$\begin{array}{l}\text { I9: Env } \\
\text { Climate change, biodiversity, and the condition } \\
\text { of natural resources, water, and soil }\end{array}$} & Q20: Nature conservation \\
\hline & & $\begin{array}{l}\text { Q21: Tools promoting nature } \\
\text { conservation }\end{array}$ \\
\hline & & $\begin{array}{l}\text { Q22: Players promoting nature } \\
\text { conservation }\end{array}$ \\
\hline & \multirow{3}{*}{$\begin{array}{l}\text { I10: Env-Soc } \\
\text { Training, consciousness, and environmental } \\
\text { culture in the territory }\end{array}$} & Q23: Nature awareness \\
\hline & & $\begin{array}{l}\text { Q24: Tools promoting nature } \\
\text { awareness }\end{array}$ \\
\hline & & $\begin{array}{l}\text { Q25: Players promoting nature } \\
\text { awareness }\end{array}$ \\
\hline
\end{tabular}




\section{REFERENCES}

[1] IEA, Hydropower, IEA: Paris, 2020. https://www.iea.org/reports/hydropower.

[2] Bartle, A., Hydropower potential and development activities. Energy Policy, 30(14), pp. 1231-1239, 2002. DOI: 10.1016/S0301-4215(02)00084-8.

[3] Rehman, S., Al-Hadhrami, L.M. \& Alam, M.M., Pumped hydro energy storage system: A technological review. Renew. Sustain. Energy Rev., 44, pp. 586-598, 2015. DOI: 10.1016/j.rser.2014.12.040.

[4] Meng, Y., Liu, J., Wang, Z., Mao, G., Wang, K. \& Yang, H., Undermined cobenefits of hydropower and irrigation under climate change. Resour. Conserv. Recycl., 167, 2021. DOI: 10.1016/j.resconrec.2020.105375.

[5] Meng, Y. et al., Hydropower production benefits more from $1.5^{\circ} \mathrm{C}$ than $2{ }^{\circ} \mathrm{C}$ climate scenario. Water Resour. Res., 56(5), 2020. DOI: 10.1029/2019WR025519.

[6] Zhou, Y. et al., A comprehensive view of global potential for hydro-generated electricity. Energy Environ. Sci., 8(9), pp. 2622-2633, 2015. DOI: $10.1039 / \mathrm{C} 5 \mathrm{EE} 00888 \mathrm{C}$.

[7] Shaktawat, A. \& Vadhera, S., Risk management of hydropower projects for sustainable development: A review. Environ. Dev. Sustain., 23(1), pp. 45-76, 2021. DOI: 10.1007/s10668-020-00607-2.

[8] Ngor, P.B., Lek, S., McCann, K.S. \&Hogan, Z.S., Dams threaten world's largest inland fishery. Nature, 563(7730), p. 184, 2018. DOI: 10.1038/d41586-018-07304-1.

[9] Gomby, G., Sand in demand: Trapped behind dams. Science, 358(6360), p. 180, 2017. DOI: $10.1126 /$ science.aap9964.

[10] Poff, N.L. \& Olden, J.D., Can dams be designed for sustainability? Science, 358(6368), pp. 1252-1253, 2017. DOI: 10.1126/science.aaq1422.

[11] Moran, E.F., Lopez, M.C., Moore, N., Müller, N. \& Hyndman, D.W., Sustainable hydropower in the 21st century. Proc. Natl. Acad. Sci. U.S.A., 115(47), pp. 1189111898, 2018. DOI: 10.1073/pnas.1809426115.

[12] Yoshida, Y. et al., Impacts of mainstream hydropower dams on fisheries and agriculture in lower Mekong basin. Sustainability (Switzerland), 12(6), p. 2408, 2020. DOI: $10.3390 /$ su12062408.

[13] Zarfl, C., Lumsdon, A.E., Berlekamp, J., Tydecks, L. \& Tockner, K., A global boom in hydropower dam construction. Aquat. Sci., 77(1), pp. 161-170, 2015.

DOI: $10.1007 / \mathrm{s} 00027-014-0377-0$.

[14] Winemiller, K.O. et al., Balancing hydropower and biodiversity in the Amazon, Congo, and Mekong. Science, 351(6269), pp. 128-129, 2016.

DOI: $10.1126 /$ science.aac7082.

[15] Pérez-Rincón, M., Vargas-Morales, J. \& Martinez-Alier, J., Mapping and analyzing ecological distribution conflicts in Andean countries. Ecol. Econ., 157, pp. 80-91, 2019. DOI: 10.1016/j.ecolecon.2018.11.004.

[16] Martínez, V. \& Castillo, O.L., The political ecology of hydropower: Social justice and conflict in Colombian hydroelectricity development. Energy Res. Soc. Sci., 22, pp. 69-78, 2016. DOI: 10.1016/j.erss.2016.08.023.

[17] Del Bene, D., Scheidel, A. \& Temper, L., More dams, more violence? A global analysis on resistances and repression around conflictive dams through co-produced knowledge. Sustain. Sci., 13(3), pp. 617-633, 2018.

DOI: $10.1007 / \mathrm{s} 11625-018-0558-1$. 
[18] Duarte-Abadía, B., Boelens, R. \& Roa-Avendaño, T., Hydropower, encroachment and the re-patterning of hydrosocial territory: The case of hidrosogamoso in Colombia. Hum. Organ., 74(3), pp. 243-254, 2015.

DOI: 10.17730/0018-7259-74.3.243.

[19] Finer, M. \& Jenkins, C.N., Proliferation of hydroelectric dams in the Andean Amazon and implications for Andes-Amazon connectivity. PLoS One, 7(4), p. e35126, 2012. DOI: 10.1371/journal.pone.0035126.

[20] Polanco, J.A., Exploring governance for sustainability in contexts of violence: The case of the hydropower industry in Colombia. Energy Sustain. Soc., 8(1), pp. 1-15, 2018. DOI: 10.1186/s13705-018-0181-0.

[21] Hidalgo-Bastidas, J. \& Boelens, R., Hydraulic order and the politics of the governed: The baba dam in coastal Ecuador. Water, 11(3), p. 409, 2019.

DOI: $10.3390 /$ w11030409.

[22] Caceres, A.L., Jaramillo, P., Matthews, H.S., Samaras, C. \& Nijssen, B., Hydropower under climate uncertainty: Characterizing the usable capacity of Brazilian, Colombian and Peruvian power plants under climate scenarios. Energy Sustain. Dev., 61, pp. 217-229, 2021. DOI: 10.1016/j.esd.2021.02.006.

[23] Henao, F., Viteri, J.P., Rodríguez, Y., Gómez, J. \& Dyner, I., Annual and interannual complementarities of renewable energy sources in Colombia. Renew. Sustain. Energy Rev., 134, 2020. DOI: 10.1016/j.rser.2020.110318.

[24] Ray, P.A. et al., Multidimensional stress test for hydropower investments facing climate, geophysical and financial uncertainty. Glob. Environ. Chang., 48, pp. 168181, 2018. DOI: 10.1016/j.gloenvcha.2017.11.013.

[25] Song, C., O’Malley, A., Zydlewski, J. \& Mo, W., Balancing fish-energy-cost tradeoffs through strategic basin-wide dam management. Resour. Conserv. Recycl., 161, 2020. DOI: 10.1016/j.resconrec.2020.104990.

[26] Siri, R., Mondal, S.R. \& Das, S., Hydropower: A renewable energy resource for sustainability in terms of climate change and environmental protection. Alternative Energy Resources. The Handbook of Environmental Chemistry, vol. 99, eds. P. Pathak \& R.R. Srivastava, Springer: Cham, pp. 93-113, 2020.

DOI: 10.1007/698_2020_635.

[27] Liden, R., Specialist, H. \& Lyon, K., The Hydropower Sustainability Assessment Protocol for Use by World Bank Clients: Lessons Learned and Recommendations, World Bank: Washington, DC, Jun. 2014.

[28] Chen, S., Chen, B. \& Fath, B.D., Assessing the cumulative environmental impact of hydropower construction on river systems based on energy network model. Renew. Sustain. Energy Rev., 42, pp. 78-92, 2015. DOI: 10.1016/j.rser.2014.10.017.

[29] UNEP Dams and Development Project, Dams and Development: Relevant Practices for Improved Decision-making: A Compendium of Relevant Practices for Improved Decision-making on Dams and their Alternatives, UNEP-DDP Secretariat: Nairobi, 2007.

[30] Nautiyal, H. \& Goel, V., Sustainability assessment of hydropower projects. J. Clean. Prod., 265, 2020. DOI: 10.1016/j.jclepro.2020.121661.

[31] Choudhury, N.B. \& Dey Choudhury, S.R., Implications for planning of hydroelectric projects in Northeast India: An analysis of the impacts of the Tipaimukh project. GeoJournal, pp. 1-21, 2020. DOI: 10.1007/s10708-020-10158-8. 
[32] Huđek, H., Žganec, K. \& Pusch, M.T., A review of hydropower dams in Southeast Europe - Distribution, trends and availability of monitoring data using the example of a multinational Danube catchment subarea. Renew. Sustain. Energy Rev., 117 p. 109434, 2020. DOI: 10.1016/j.rser.2019.109434.

[33] Assessment Protocol (HSAP), Hydropower sustainability tools. https://www.hydrosustainability.org/assessment-protocol.

[34] Wang, C., A Guide for Local Benefit Sharing in Hydropower Projects, World Bank: Washington, DC, 2012.

[35] Jiménez-Inchima, I., Polanco, J.A. \& Escobar-Sierra, M., Good living of communities and sustainability of the hydropower business: Mapping an operational framework for benefit sharing. Energy Sustain. Soc., 11(1), p. 9, 2021.

DOI: $10.1186 / \mathrm{s} 13705-021-00284-7$.

[36] Polanco, J.A. \& Ramírez Atehortúa, F.H., Evaluación de la Sostenibilidad en Empresas de Energía: Una Investigación Aplicada a Centrales de Generación Hidroeléctrica, Universidad de Medellín, 2017.

[37] Hydropower status report. https://www.hydropower.org/publications/2016hydropower-status-report.

[38] Quiceno, G. et al., Scenario analysis for strategy design: A case study of the Colombian electricity industry. Energy Strateg. Rev., 23, pp. 57-68, 2019.

DOI: 10.1016/j.esr.2018.12.009.

[39] Sierra, M.C., Ramos, J., Jurado, D. \& Herrera, J.D., Practical solutions to geotechnical problems related to Ituango hydropower tunnels, Colombia. Tunnels and Underground Cities: Engineering and Innovation meet Archaeology, Architecture and Art - Proceedings of the WTC 2019 ITA-AITES World Tunnel Congress, pp. 1144-1152, 2019.

[40] Pérez-Rincón, M., Vargas-Morales, J. \& Crespo-Marín, Z., Trends in social metabolism and environmental conflicts in four Andean countries from 1970 to 2013. Sustain. Sci., 13(3), pp. 635-648, 2018. DOI: 10.1007/s11625-017-0510-9.

[41] Cernea, M.M., Hydropower dams and social impacts: A sociological perspective (English). Environment Department Working Papers; no. 44, Social Assessment Series*Social Development Papers; no. SDP 16, World Bank Group: Washington, D.C., 1997.

[42] Lindgreen, A., Córdoba, J.-R., Maon, F. \& Mendoza, J.M., Corporate social responsibility in Colombia: Making sense of social strategies. J. Bus. Ethics, 91(2), pp. 229-242, 2010. DOI: 10.1007/s10551-010-0616-9.

[43] Polanco, J.A., The group EPM social responsibility: A new political stance against the territory. Cuad. Adm., 27(49), pp. 65-86, 2014. DOI: $10.11144 /$ Javeriana.cao27-49.

[44] Duque Grisales, E.A., The clean development mechanism as a means to assess the Kyoto protocol in Colombia. Int. J. Renew. Energy Res. IJRER, 7(3), 2017.

[45] Del Río, D.A., Moffett, H., Nieto-Londoño, C., Vásquez, R.E. \& EscuderoAtehortúa, A., Chivor's Life Extension Project (CLEP): From sediment management to development of a new intake system. Water, 12(10), p. 2743, 2020. DOI: $10.3390 / \mathrm{w} 12102743$.

[46] Del Río, D.A., Moffett, H., Nieto-Londoño, C., Vásquez, R.E. \& EscuderoAtehortúa, A., Extending life expectancy of La Esmeralda reservoir: A bet to support Colombia's future energy demand. American Society of Mechanical Engineers, Power Division (Publication) POWER, 2020. DOI: 10.1115/POWER2020-16918. 
[47] Botero, B.A., Parra, J.C. \& Otálvaro, M., Effect of population dynamics and land use on the contribution of sediments to reservoirs for hydropower generation. WIT Trans. Ecol. Environ., 239, pp. 35-46, 2019. DOI: 10.2495/WS190041.

[48] Rodríguez-de-Francisco, J.C., Duarte-Abadía, B. \& Boelens, R., Payment for ecosystem services and the water-energy-food nexus: Securing resource flows for the affluent? Water, 11(6), p. 1143, 2019. DOI: 10.3390/w11061143.

[49] Roa-García, M.C. \& Brown, S., Assessing equity and sustainability of water allocation in Colombia. Local Environ., 22(9), pp. 1080-1104, 2017. DOI: 10.1080/13549839.2015.1070816.

[50] Sierra, R.G. \& Sarmiento, Á.Z., New advances in decision making theory under uncertainty and its application in mega projects of hydropower. World Trans. Eng. Tech. Edu., 14(2), 2016.

[51] Polanco, J.A., Ramírez-Atehortúa, F.H., Montes-Gómez, L.F., Botero-Hernández, B.A. \& Barco, M.O., Effect of sediment management decision on a hydropower plant value. Dyna. Rev. Fac. Nac. Minas, 87(213), pp. 232-240, 2020. DOI: $10.15446 /$ dyna.v87n213.81832.

[52] Lütjohann, H., The stepwise regression algorithm seen from the statistician's point of view. Metr. Int. J. Theor. Appl. Stat., 15(1), pp. 110-125, 1970.

DOI: $10.1007 / \mathrm{BF} 02613564$. 